\section{AB0756 COMPARATIVE CHANGE IN QUALITY OF LIFE MEASURES IN PRECLINICAL AND ESTABLISHED PSORIATIC ARTHRITIS PATIENTSUNDER SECUKINUMAB TREATMENT. DATA DERIVED FROM THE PROSPECTIVE OPEN LABEL PSARTROS STUDY}

Eleni Kampylafka ${ }^{1}$, Matthias Englbrecht ${ }^{2}$, Koray Tascilar ${ }^{2}$, Veronika Lerchen ${ }^{2}$, Christina Linz ${ }^{2}$, Arnd Kleyer ${ }^{2}$, David Simon ${ }^{2}$, Jürgen Rech ${ }^{2}$, Georg Schett ${ }^{2}$, Axel Hueber ${ }^{2,3} \cdot{ }^{1}$ Friedrich-Alexander University Erlangen-Nürnberg and Universitätsklinikum Erlangen, Department of Internal Medicine 3 - Rheumatology and Immunology, Erlangen, Germany; ${ }^{1}$ Friedrich-Alexander University ErlangenNürnberg and Universitätsklinikum Erlangen, Department of Internal Medicine 3 Rheumatology and Immunology, Erlangen, Germany; ${ }^{3}$ Sozialstiftung Bamberg, Bamberg, Germany

Background: Psoriasis $(\mathrm{PsO})$ and psoriatic arthritis ( $\mathrm{PsA}$ ) differentially impact patients' quality of life (QoL) due to pain, mental changes in the context of chronic inflammation and impaired physical function. Effective anti-inflammatory therapy has shown to be effective to improve QoL in PsO and PsA patients. However, the impact of ant-inflammatory therapy on QoL may be different in the earliest stages of PsA as compared to established disease.

Objectives: To perform a detailed comparative investigation of the effect of interleukin (IL)-17 inhibition with $300 \mathrm{mg}$ secukinumab (SEC) on QoL in patients with very early PsA/pre-PsA and established PsA.

Methods: Patients from the IVEPsA study (1) on very early PsA/pre-PsA $(\mathrm{N}=20)$ and the PSARTROS (2) study on established PsA $(\mathrm{N}=20)$ were longitudinally assessed for SF-36, DLQI, PSAID and HAQ-DI at baseline and after 4, 12 and 24 weeks. All patients received SEC treatment; 19/ 20 pre-PsA patients and 17/20 established PsA patients completed the study. Changes from baseline values were evaluated using linear mixed effects models adjusted for baseline values of each scale, gender, age and disease duration, and plotted as model coefficients and respective $95 \%$ confidence intervals that represent adjusted mean absolute improvement from baseline. Scale signs were inverted as necessary to ease interpretability. Further subgroup analysis was conducted using MannWhitney.

Results: Significant and rapid improvements were observed in both prePSA and established PSA treated with SEC with regard to pain (SF-36 bodily pain, BP), general health perception $(\mathrm{GH})$, dermatology quality of life index (DLQI) and PsA impact of disease (PsAID), as well as in the SF-36 component scores (mental component score of SF-36, MCS and physical component score of SF-36, PCS). Physical function- oriented instruments like SF-36 physical functioning (PF), role limitation due to physical problem (RP) and HAQ-DI were preferentially affected in established PSA group due to the higher functional burden of disease (Figure). There were more differences with respect to the course of QoL improvements through week 12 and 24, as established PsA patients showed an incremental improvement in SF-36 BP, PF and GH from week 12 to 24 while most of the responses plateaued in the pre-PsA group. Furthermore, established PsA patients who achieved minimal disease activity showed a significantly higher improvement in PsAID, HAQ-DI, SF-36 PF, $\mathrm{RP}$ and BP (all $\mathrm{p}<0.05$ ).

Conclusion: Pain, mental health, general health perception and impact of disease rapidly improve in both very early PsA/pre-PsA and established PsA patients treated with SEC. These data support the concept that very early treatment of PsA leads to significant improvement in QoL with the additional benefit of prevention of bone damage as previously shown $(1$, 2).

\section{REFERENCES}

1. OP0305 Disease interception in psoriasis patients with subclinical joint inflammation by interleukin 17 inhibition with secukinumab - data from a prospective open label study. Kampylafka et al, ARD June 2018, Volume 77, Suppl. 2

[2] Resolution of synovitis and arrest of catabolic and anabolic bone changes in patients with psoriatic arthritis by IL-17A blockade with secukinumab: results from the prospective PSARTROS study. Kampylafka et al, Arthritis Res Ther. 2018 Jul 27;20(1):153

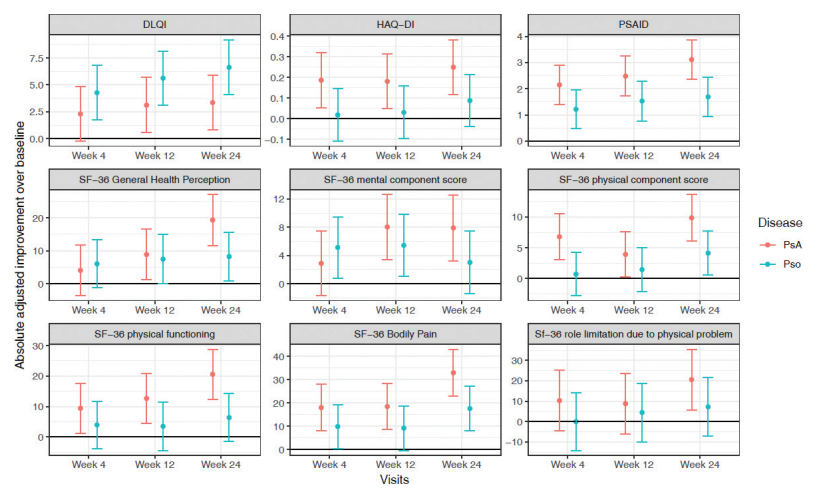

Figure:

Acknowledgement: This study was supported by an unrestricted grant from Novartis.

Disclosure of Interests: Eleni Kampylafka: None declared, Matthias EngIbrecht Grant/research support from: Roche Pharma AG, Chugai Pharma Europe Ltd., Consultant for: Roche Pharma AG, Chugai Pharma Europe Ltd., AbbVie Deutschland $\mathrm{GmbH}$ \& Co. KG, Celgene $\mathrm{GmbH}$, Lilly Deutschland $\mathrm{GmbH}$, Speakers bureau: Roche Pharma AG, Chugai Pharma Europe Ltd., AbbVie Deutschland $\mathrm{GmbH}$ \& Co. KG, Celgene $\mathrm{GmbH}$, Lilly Deutschland $\mathrm{GmbH}$, Koray Tascilar: None declared, Veronika Lerchen: None declared, Christina Linz: None declared, Arnd Kleyer Grant/research support from: Lilly, Consultant for: Lilly, Speakers bureau: Abbvie, David Simon Grant/research support from: Novartis, Consultant for: Lilly, Speakers bureau: Janssen, Jürgen Rech Grant/research support from: Bristol-Myers Squibb and Celgene (greater than \$10,000), Consultant for: Bristol-Myers Squibb, Celgene, Chugai, GlaxoSmithKline, Janssen, Eli Lilly, Novartis, Roche, Sanofi Aventis, and UCB (in total more than $\$ 10,000)$, Speakers bureau: Bristol-Myers Squibb, Celgene, Chugai, GlaxoSmithKline, Janssen, Eli Lilly, Novartis, Roche, Sanofi Aventis, and UCB (in total more than \$10,000), Georg Schett: None declared, Axel Hueber Grant/research support from: Novartis, Pfizer, Consultant for: Lilly, Speakers bureau: Lilly, Novartis, Janssen, Abbvie

DOI: 10.1136/annrheumdis-2019-eular.2628

\section{AB0757 ANALYSIS OF THE PROGNOSTIC VALUE OF THE 12- ITEM PSORIATIC ARTHRITIS IMPACT OF DISEASE (PSAID-12) QUESTIONNAIRE FOR EVALUATION OF PSORIATIC ARTHRITIS ACTIVITY(PSA) BY DISEASE ACTIVITY INDEX FOR PSORIATIC ARTHRITIS (DAPSA) IN ROUTINE CARE: DATA OF THE RUSSIAN PSORIATIC ARTHRITIS REGISTRY(RU-PSART)}

Anastasia Koltakova ${ }^{1}$, Elena Loginova ${ }^{1}$, Elena Gubar ${ }^{1}$, Yulia Korsakova ${ }^{1}$,

Tatiana Korotaeva ${ }^{1}$, Maria Sedunova ${ }^{2}$, Igor Pristavsky ${ }^{2}$, Irina Umnova ${ }^{3}$,

Irina Bondareva ${ }^{4}$, Snezana Kudishina ${ }^{5}$, Evgeny Nasonov ${ }^{2} .{ }^{1}$ Nasonova Research Institute of Rheumatology, Moscow, Russian Federation; ${ }^{2}$ St. Petersburg Clinical Rheumatology Hospital No.25, St. Petersburg, Russian Federation; ${ }^{3}$ Omsk Regional Hospital, Omsk, Russian Federation; ${ }^{4}$ Kemerovo Regional Hospital, Kemerovo, Russian Federation; ${ }^{5}$ Vladivostok Clinical Hospital No.2, Vladivostok, Russian Federation

Background: The PSAID-12 is an instrument for assessment the impact of PsA on patients' lives by examine both physical and psychological components of health. DAPSA is a valid and discriminative tool for evaluation of the PSA activity. There is limited data about the PSAID-12 correlations with PSA activity by DAPSA in clinical care [1].

The Russian Psoriatic Arthritis Registry (RU-PsART) collected data from 25 rheumatology clinics in the Russian Federation regions.

Objectives: to investigate the predictive value of the PsAID-12 for evaluate PsA activity by DAPSA in real-world settings.

Methods: 138 (male/female-79/59) patients (pts), median age 40 (MinMax/23-71), with PsA, according to CASPAR criteria, were included in 